\title{
O PORTUGUÊS QUE A ESCOLA FALA: UM RELATO DE EXPERIÊNCIA SOBRE O CONCEITO DE LÍNGUA PORTUGUESA NA ESCOLA PÚBLICA
}

\author{
Jadson Lima Jesus da Silva ${ }^{1}$ \\ Lenilza Teodoro dos Santos Mendes ${ }^{2}$
}

RESUMO: Este trabalho é fruto das experiências obtidas no estágio supervisionado em Língua Portuguesa pela Universidade Estadual de Santa Cruz - UESC. A turma na qual o trabalho foi realizado é do 6ㅇ ano do Ensino Fundamental II, da Escola Municipal São Pedro em Ilhéus-BA. Buscamos com este relato compartilhar e fomentar discussões acerca do conceito de língua na escola. O trabalho aqui apresentado tece algumas considerações sobre a maneira errônea como a gramática tradicional defrauda para si o conceito de língua. Ademais, apresentamos aspectos relacionados à descrição do local, aulas, métodos utilizados, resultados obtidos, e uma reflexão sobre o conceito de língua nas aulas de Língua Portuguesa.

Palavras-Chave: Ensino. Língua Portuguesa. Concepção de Língua. Escola Pública.

\section{THE PORTUGUESE SPOKEN AT SCHOOL: AN EXPERIENCE REPORT ABOUT THE CONCEPT OF PORTUGUESE LANGUAGE AT SCHOOL}

ABSTRACT: This work is the result of the experiences obtained in the supervised stage in Portuguese Language by the State University of Santa Cruz - UESC. The class in which the work was carried out is the 6th year of Elementary School, São Pedro Municipal School located in Ilhéus-BA. We seek with this report to share and warm up discussions about the concept of language in school. This work presents some considerations about the erroneous way in which traditional grammar takes the concept of language for itself. In addition, we present some aspects related to the school, classes, methods used on it, obtained results, and a reflection on the concept of language in Portuguese classes.

Keywords: Teaching. Portuguese language. Concept of Language. Public school.

\footnotetext{
${ }^{1}$ Graduando de Letras com habilitação em línguas e literaturas portuguesa e inglesa na Universidade Estadual de santa Cruz - UESC. Email: jds.limaios@hotmail.com

${ }^{2}$ Professora assistente na Universidade Estadual de santa Cruz - UESC, e doutora em Língua e Cultura pela Universidade Federal da Bahia - UFBA. Email: lenilzate7@gmail.com
} 


\section{INTRODUÇÃO}

De acordo com os Parâmetros Curriculares Nacionais - PCN, o ensino de Língua Portuguesa (LP) deve ser pautado num ensino que apresente aos alunos a variedade linguística e os auxilie no desenvolvimento de um olhar crítico sobre a própria língua. Todavia, a proposta parece não ser compreendida pela escola, uma vez que o ensino de LP continua engessado e ultrapassado. A causa dessa (trava) ocorre porque a escola persiste em manter uma concepção de língua centrada unicamente na gramática tradicional como salienta Bezerra (2002).

Quando a escola concebe língua apenas sob a ótica da gramática tradicional, ela propõe aos alunos que: estudar/aprender língua resume-se a memorização de regras as quais auxiliam na identificação e atribuição de funções sintáticas às palavras. Essa adoção de conceito de língua é totalmente exclusora, dado que não abarca a real utilidade da língua. Alunos e escola, em especial as aulas de LP, se desencontram nesse contexto, uma vez que a língua falada pelos alunos é posta de lado no ambiente escolar, e dá espaço a um modelo de língua padrão que supostamente serve de base para uma comunicação coletiva e eficaz. Levando em consideração esse contexto, pode-se observar que o português que a escola fala não condiz ao português utilizado pelos estudantes.

Tendo pensado sobre essas questões, este relato é resultado da experiência obtida no estágio de Língua Portuguesa II, no qual tive minha primeira prática no ensino de língua materna; aqui apresentamos uma análise acerca de como a LP é vista pelos alunos na Escola Municipal do Salobrinho em Ilhéus/BA. Durante o período de estágio acompanhei uma turma de alunos do 6ㅇ ano do ensino fundamental com a faixa etária de 11 a 12 anos. Como maioria das crianças dessa idade, são elas: questionadoras, sedentas por informações e donas dos incansáveis "porquês"; foi justamente essa atitude que me fez pensar numa (abordagem) de ensino que as levasse a refletir o conceito de língua.

A necessidade desse trabalho se faz uma vez que, no período de estágio supervisionado em LP constatou-se que alunos apresentam visões limitadas sobre o conceito de língua, o que interfere diretamente no modo como a Língua Portuguesa é ensinada na escola pública. Por vezes, alunos são submetidos a aulas monótonas, e os professores por 
sua vez facejam o amargor de aulas improdutivas; toda essa estrutura pode vir a ser melhor organizada se novas concepções de ensino de língua chegarem à escola pública.

Esperamos com este relato fomentar as discussões acerca do ensino de língua materna no Brasil, e principalmente colaborar, por meio de experiência tida, na construção de um conceito de língua em que os alunos se sintam inseridos; que este os faça compreender que são eles construtores da própria língua.

\section{METODOLOGIA}

O estágio de LP teve seu início no dia 8 de abril e findou-se em 19 de junho, nesse período, foram propostas três etapas: (I) Observação, na qual o estagiário se familiariza com membros da escola, alunos, professor regente e os métodos utilizados por ele nas aulas. (II) Coparticipação, o estagiário auxilia o professor regente nas aulas, esclarecendo dúvidas de alunos acerca dos assuntos e atividades propostas. (III) Regência, por fim, a última etapa se efetiva na prática da docência por parte do estagiário, cabendo ao professor regente acompanhar e avaliar o trabalho desenvolvido pelo universitário.

No que diz respeito à escola escolhida, esta possui uma estrutura física mediana. Quatro salas de aulas amplas e duas de menor tamanho, uma sala multimídia, dois banheiros, pátio, uma sala de atendimento educacional especializado e uma sala em que funciona a direção, coordenação e sala dos professores.

A proposta de ensino adotada fora voltada à construção de um conceito de língua que abrangesse a língua usada pelos alunos no cotidiano, a turma em questão, como citada anteriormente, era do 60 ano do ensino fundamental II. Amparamos nossa proposta de ensino em pressupostos da Sociolinguística, a temática da variação linguística fora utilizada como meio de mostrar as mais variadas formas de falar uma mesma língua. Por serem crianças e não possuírem aproximação com as discussões que cercam o conceito de língua, o trabalho se efetivou com o auxílio de textos do livro Cultura da Terra (2008) do escritor Ricardo Azevedo, o qual gira em torno da cultura popular brasileira; utilizamos lendas e ditos populares para aproximar as crianças do tema, uma vez que os textos escolhidos possuíam marcas orais de cada região do país.

Assim que iniciada a etapa da regência em sala, os alunos foram convidados a pensar sobre um conceito de língua. Numa roda de conversa cabia a eles apresentar suas 
opiniões sobre o que seria estudar Língua Portuguesa na escola, qual a função dela e de que maneira essa seria importante para vida. A maior parte da turma sinalizou que estudar a língua materna significava gravar as regras gramaticais e conseguir falar corretamente (isso é, sob a perspectiva da gramática tradicional). Outras opiniões se referiam à ideia de que o estudo da LP na escola tinha relação direta com a quantidade de leitura e escrita feita durante as aulas.

Sendo os alunos provenientes de uma zona rural da cidade, a ideia de língua que levam para a sala de aula se restringe à gramática tradicional. Quando questionados sobre a maneira como falam (língua que usam) no dia a dia com amigos e familiares, os estudantes admitiram que possuíam uma "língua", porém, a consideravam errada e incompleta, por isso estavam na escola. Pensando nessa lógica, os alunos compreendem que a prática da escrita e leitura na escola é o que permite a aprendizagem correta da língua. Depois de colocadas em questão algumas crenças sobre o ensino-aprendizado de LP, nossas conversas foram, ao decorrer das aulas, direcionadas à temática da variação linguística.

Quanto ao conceito de língua, ao decorrer das discussões, pôde-se observar que os alunos compreendem língua como um conjunto de palavras faladas por eles no dia a dia, e que tais palavras precisam da escola para serem efetivadas como língua, uma vez que, somente no espaço escolar "aprenderão" a falar corretamente. O conceito de língua obtido ao longo das conversas com os alunos, nos remete ao ponto central desse relato de experiência: escola e alunos falam e pensam a LP da mesma forma?

Outra visão de língua observada nas aulas é que, alguns dos alunos limitavam língua unicamente à escrita. Isso se, tal escrita fosse gramaticalmente correta, o que por vezes invalidou alguns textos trabalhados no livro de Ricardo Azevedo, já que apresentavam marcas de oralidade. Foi por meios desse conceito, que a variação linguística ganhou espaço inicial na sala de aula.

De modo simplista os livros didáticos (LDs) pincelam sobre a importância do respeito às outras variantes linguísticas, porém o assunto é rapidamente ofuscado pelas atividades gramaticais propostas nos livros. Soa irônico tratar de variação linguística com os alunos, sendo que a escola com o auxílio dos LDs, por vezes, invalida as variantes usadas pelos próprios alunos. Determinados falantes, a depender de seu nível socioeconômico, dizem: "Nóis vai para a escola", e o professor munido com livro sinaliza: "Nós vamos". 
Inicialmente o assunto causou desconforto nos alunos, afinal o conceito de "erro" gramatical empregado na escola se faz de modo rígido, dessa forma, foi difícil fazer com que os alunos compreendessem que os "deslizes" cometidos na fala é parte de uma discussão importante. Levei para a sala de aula discussões sobre diferentes variantes linguísticas, imbricando-as com a concepção de erro gramatical. De modo custoso, foi possível alertar aos alunos sobre a existência de outras formas de usar uma língua, tomando como exemplo o próprio diálogo utilizado por eles na discussão.

Depois de compreendido que a noção de erro deve ser vista de modo cauteloso, as aulas seguintes voltaram-se à temática das culturas populares existentes no Brasil. Utilizamos lendas, mitos, contos e cordéis como meio de mostrar a pluralidade cultural existente no país e, mediante isso, explicitar as diferentes formas como uma mesma língua ganha contornos quando em diferentes contextos sociais.

Quando colocados diante dos textos, os alunos acabaram por trazer à tona a dicotomia língua padrão $\mathrm{X}$ língua coloquial. Como indagada por muita gente que possui um contato inicial com a temática, pairou-se a dúvida: se tudo é variação, para que as aulas de LP? Diante do questionamento, uma das aulas fora voltada à discussão do tema, sinalizando a eles que a função proposta para o ensino da norma culta é de auxiliar no entendimento de todos os falantes, independentemente do contexto social e econômico no qual o sujeito está inserido.

Outro ponto importante, no plano de ensino proposto, gira em torno dos trabalhos com gêneros escritos e orais; incialmente a desconstrução de que escrita possui um valor maior em detrimento da fala, ademais, mostrar que os gêneros orais também são fontes que auxiliam na aprendizagem da própria língua. Os gêneros escolhidos para trabalhar são híbridos, pois unem escrita e fala: contos populares, lendas, mitos e vídeos foram utilizados como canal para tratar da temática maior do plano de ensino, o conceito de língua usado na escola.

No que tange às atividades, distanciamos um pouco do método utilizado pelo professor regente. Foi dada uma atenção maior à oralidade em sala, afinal seria incoerente tratar de conceito de língua, variação linguística e gêneros orais atendo-se a atividades escritas. A turma foi dividida em cinco grupos, cada grupo era responsável por compartilhar oralmente, mediante a escolha de um gênero oral, alguma lenda regional que conhecessem. 
Um grupo optou por relato pessoal, outros dois apresentaram as lendas regionais por meio de reportagem televisiva e os demais seguiram por meio de contação de histórias.

Como sinalizado anteriormente, as rodas de conversas tinham como objetivo auxiliar na desconstrução de crenças sobre o conceito de língua que, erroneamente, a escola fomenta, dando atenção unicamente à gramática tradicional. Por isso, trabalhar variação linguística por meio de contação de lendas e mitos presentes no livro Cultura da terra, serviu para evidenciar que a Língua Portuguesa possui contornos que fogem à norma-padrão apresentada pela escola.

Nas aulas finais do estágio supervisionado, as atividades passaram a ter um caráter mais lúdico. Foram utilizados jogos e dinâmicas como meio de consolidar as discussões e atividades realizadas no decorrer das aulas. Tomando como exemplo o jogo Twister, que apesar de se direcionar a trabalhar com habilidades corporais, foi totalmente adaptado para as aulas, aliando assuntos gramaticais propostos para série escolar com a temática da variação linguística. Cada participante fazia uma pergunta ao seu oponente, caso errasse, deveria cumprir o desafio proposto na roleta do jogo Twister. Por exemplo: "Qual outra forma podemos utilizar para se referir ao personagem da lenda no Negro da água?" O aluno deveria responder "Nego D'água" termo que mais se aproxima da realidade dele.

Já o Jogo das palavras, consistia em um trabalho em grupo, no qual os alunos deveriam formar palavras com letras recortadas em cartolina. Por exemplo, durante a aula foi retirado do livro o trecho "Meu avião avoa do sul pro norte"; tendo compartilhada a frase, foi pedido aos alunos que formassem (com as letras) uma conjugação do verbo voar que melhor se adequasse a frase, mediante a gramática tradicional. Creio que esses dois jogos foram importantes pois direcionavam os alunos a pensar na Língua Portuguesa sobre as duas óticas: coloquial e padrão, sem que uma deslegitimasse a outra.

Também foi feita a dinâmica dos quadrados, que serviu para a explicação de assuntos gramaticais tidos como os mais difíceis pela turma, como verbos, adjetivos substantivos etc. Seguindo a mesma premissa dos jogos anteriores, este uniu gramática e cultura popular. A dinâmica consistia em fazer com que os alunos caminhassem até um dos dois pontos da sala, que equivaliam às respostas "sim" e "não". Foi utilizada a seguinte frase durante a dinâmica: "Com seus cabelos vermelhos e pés para trás, ele percorre toda a mata" logo em seguida, foi dito: "A palavra trás é um verbo! " Caso os alunos concordassem com a 
afirmação, deveriam correr para o lado "sim" da sala, e se discordassem iriam para o lado oposto. Tendo os alunos escolhido suas respostas, o professor pedia para que um aluno de cada equipe explicasse suas escolhas, baseando-se nos estudos feitos.

Para além dos jogos e dinâmicas, outros materiais foram utilizados nas aulas. O livro didático foi trabalhado como apoio na a realização das tarefas gramaticais, quase sempre direcionadas para serem feitas em casa. O livro Cultura da Terra fora utilizado em sala de aula, nas atividades de leituras de lendas e mitos, também como meio de evidenciar as variantes linguísticas presentes no país. Para além, materiais como cartolinas, lápis de cor, giz de cera, hidrocor e cola foram usados para a confecção das letrinhas usadas no jogo das palavras. Por fim, folhas de atividades e a lousa como material de apoio.

\section{RELATO DE EXPERIÊNCIA}

Soa inútil pensar o ensino de línguas sem compreender um pouco das concepções que professores e alunos possuem sobre ela. Assim sendo, só é possível falar das limitações que o ensino de Língua Portuguesa sofre nas escolas públicas se atentarmos ao modo como o professor enxerga aspectos que compõem dada língua.

Um dos aspectos mais importantes que estão imbricados à língua é a cultura. Pensar as aulas de português sem pensar as culturas nas quais os alunos estão inseridos acaba por seu uma tarefa ineficiente, as aulas assumem um papel puramente mecânico. Segundo Cuche (2002, citado por Boas, 2004), "Cada cultura é dotada de um estilo particular que se exprime através da língua, das crenças, dos costumes, também da arte, mas não apenas desta maneira. Este estilo, este espírito próprio de cada cultura influi sobre o comportamento dos indivíduos". O que ocorre é que a escola em nome de uma homogeneidade linguística marginaliza a variante falada pelos alunos fora do ambiente escolar, ação que acarreta a exclusão das culturas destes.

Do primeiro ao último dia, o estágio supervisionado mostrou-se um desafio para mim. Seria minha primeira experiência como professor de língua materna. No período de observação atentei-me ao máximo aos passos dados pela professora com o intuito de compreender bem como funcionam as aulas de LP. Questionava-me como poderia eu levar à frente o ensino de língua materna sabendo que já estava perpassado por outras concepções de língua; estaria eu a ensinar realmente a Língua Portuguesa? Para Görski \& Coelho (2009, 
p.83) o que se ensina na escola é uma variante padrão da língua, não exatamente o ensino de língua materna; é nesse ponto que a LP ganha contorno desconhecido, soando às vezes como uma língua estrangeira para os alunos.

No primeiro dia em que fui apresentado à turma fiquei surpreso, pela primeira vez em minha vida havia visto uma sala que pareceria não se importar com um corpo estranho em meio a eles. Nada de perguntas, apenas um silêncio rápido seguido do barulho normal feito por eles. Sentado numa das carteiras no canto da sala, observei como seria a experiência de ser professor deles.

Barulho: essa palavra define ao máximo a turma de 6ํㅜ ano na qual fui estagiário. Diversas vezes a professora regente gastou cerca de 25 minutos para conseguir iniciar as aulas; eu ali parado observava e pensava numa maneira de conseguir reduzir esse tempo quando desse início à minha regência, entretanto era difícil pensar em algo, afinal 28 crianças falavam alto e gritavam ao mesmo tempo.

As aulas tinham início depois dos ânimos acalmados. A professora regente fazia a chamada (lista de frequência) e com o decorrer do tempo observamos (a professora e eu) que aquela era a melhor maneira de controlar o barulho da turma no início das aulas. Quanto às tarefas escolares, essas seguiam o mesmo padrão: lousa - caderno, as propostas de atividades eram voltadas à reescrita de texto, ditados e identificação e atribuição das funções sintáticas das palavras.

O ensino de gramática se faz de modo incisivo nas aulas de LP; decorar regras gramaticais, identificar e dar funções às palavras avulsas encontradas em textos são as atividades comumente realizadas, e que no estágio supervisionado pude constatar. Não é uma discussão nova, mas volto a problematizar: é preciso que a escola questione de que modo a memorização de uma oração coordenada sindética conclusiva irá interferir de modo significativo no ensino de língua. Waal (2009. p. 287) convida-nos à discussão quando sinaliza sobre a função que a escola tem e atenta quanto à insistência da escola em pensar a gramática como ponto principal para o desenvolvimento linguístico dos alunos.

Se questionarmos a função da escola para com as nossas crianças, a resposta será unânime, ensinar a leitura e a escrita. Para desenvolver essa função, a escola utiliza a gramática como ponto de partida, a qual passa a ocupar papel central no processo de ensino/aprendizagem, pois se acredita que para a criança aprender a ler e a escrever, a mesma precisa dominar a gramática da língua. 
O autor também sinaliza que a maneira como a gramática é ensinada não contribui com a proposta de ensino de Língua Portuguesa, afinal a função do ensino de LP seria proporcionar o desenvolvimento da competência linguística dos alunos (WAAL, 2009, p. 287). Desse modo, pensando na função principal do ensino de língua materna na escola, conclui-se, assim como o autor, de que o ensino puro da gramática acaba por ser uma tarefa sem utilidade.

Dividida em três partes, a lousa juntamente com o marcador eram os principais recursos didáticos das aulas. A professora copiava as questões na lousa e ia apagando mediante a permissão dos alunos. Metaforicamente aquilo mais parecia uma ópera, o barulho do marcador riscando o quadro, ventiladores giravam num som entediante e um grande coral dos mais timbres de voz reclamando sobre a quantidade de tarefas a serem copiadas. O retrato real de muitas aulas de português em escolas públicas. Depois de terminada essa parte, a professora iniciava as explicações do assunto e auxiliava na resolução das atividades.

Voltando um pouco à ópera que citei acima, eu, estagiário, assistia a tudo aquilo um pouco enfadado; beirando ao ponto de não saber se estava me preparando para ser um professor ou estava voltando a viver meus tempos da antiga 5a série. Uma década se passou desde que saí daquela série, mas ao chegar ao estágio percebi que pouca coisa mudou, o mesmo método de ensino continua vigente nas aulas de LP e a gramática tradicional continua a ser o principal objeto estudado.

Mesmo com as inúmeras discussões acerca de novas abordagens de ensino de LP, certo é que a gramática tradicional continua a ocupar um espaço muito grande nas aulas. Antunes (2007) afirma que o problema ocorre devido à ideia errônea de que língua é gramática. Dessa forma, nas aulas de português é ensinada gramática pensando estar ensinando português.

Para Barbosa e Cuba $(2015$, p. 80) "Aprender a falar direito" é uma das crenças propagada por alunos quando são indagados quanto a função da escola e das aulas de português. Essa confusão se dá exatamente porque a escola continua a ascender uma norma padrão em detrimento das variantes que os alunos possuem. Não é que a gramática deva ser banida das aulas de LP, o que se espera é que o conceito de língua seja ampliado, dessa 
forma serão possíveis abordagens mais produtivas de ensino de línguas. Como bem sinaliza Bagno (1999, p. 52): "É claro que é preciso ensinar a escrever de acordo com a ortografia oficialmente, mas não se pode fazer isso tentando criar uma língua falada "artificial" e reprovando como "erradas" as pronúncias que são resultados natural das forças internas que governam o idioma".

Madeira (2005) realizou uma pesquisa a fim de identificar crenças de professores de português e o papel que a gramática exerce no ensino de LP. Dentre os resultados obtidos, destacou-se que uma grande parcela (91\%) dos professores entrevistados concorda que é preciso aceitar de forma natural os "erros" que os alunos cometem, afinal é por meio dos erros que se aprende. Provável que a justificativa ("é errando que se aprende") dada pelos professores não se adeque por completo à noção de língua proposta nesse trabalho, já que nas respostas dos professores é possível perceber que a concepção de "erro" que possuem está centrada no que dita à gramática tradicional. Porém, ainda assim, o resultado da pesquisa sinaliza que as discussões que giram em torno do conceito de língua têm surtido efeitos positivos.

O período de observação foi de grande importância; sem ele seria impossível a aplicação do plano de ensino proposto inicialmente. Depois de acompanhada mais a fundo a realidade da sala em que estagiei, direcionei as últimas aulas para uma abordagem mais lúdica, livre da gramática explícita.

Após acompanhar a turma por 13 aulas, deu-se o início à coparticipação. Deixei de lado a cadeira e passei a ajudar a professora com as aulas e atividades. Creio que, dentre as etapas do estágio, a coparticipação foi a mais enriquecedora para mim. Nela fui parte dos alunos, diferentemente do que ocorreu na regência, uma vez que eu era visto pelos alunos como professor.

O contato direto com a turma proporcionado pela coparticipação me fez entender um pouco dos pensamentos deles quanto às aulas de português. Sempre que eu me direcionava a um dos alunos para ajudar com as lições percebia frustração por parte deles, o mesmo sentimento que tinha quando estava naquela série escolar. Olhar para um conjunto de atividades que mesmo escritas em português, parecia grego é de fato assustador. Nesse tempo em que ajudei a professora, percebi que meu plano reelaborado seguiria no caminho certo; trabalhar a carência dos alunos quanto ao real significado de língua, fazê-los 
compreender que não são sujeitos distantes da própria língua, muito pelo contrário, são agentes ativos na construção dela, como bem frisa Resende (2009) ao suscitar os estudos de sociointeracionistas de Vygotsky.

Minha regência teve início após 28 aulas com essa turma. 0 primeiro dia de aula foi uma correria, a simples mudança de layout da sala já causou muito barulho. A aula foi trabalhada em círculo, o que parecia ser novidade para a turma. Aos poucos, fui percebendo que eram tímidos (o que é irônico) quando precisavam falar em público sobre suas experiências com as aulas de LP.

A etapa de regência foi marcada por muitos altos e baixos. De maneira custosa, consegui obter respostas dos alunos sobre as nossas discussões em que boa parte se mostrava relutante, raramente gostavam de trabalhar em grupo. Sou ciente de que minhas aulas corriam de encontro a um sistema sólido presente na escola; imaginar aulas de português que foge à lousa, cadeiras enfileiradas e livros cheios de texto é bem difícil, porém não é impossível.

Ocorreram também aulas produtivas, essas me serviram de gás para dar continuidade ao trabalho desenvolvido. Em algumas aulas, fui percebendo a empolgação da turma para produzir textos orais, os quais abordavam a temática da variação linguística e se efetivaram por meio do compartilhamento de lendas regionais. Deixei de lado um pouco a lousa e dei voz às crianças, trabalhei língua sobre outra ótica, dei espaço à oralidade, que por muitas vezes é excluída da sala de aula, como bem sinaliza Suassuna (1995, p. 35): "No que tange à oralidade, vemos que ela praticamente não tem lugar nesse modelo de ensino, talvez até por se acreditar que os alunos já sabem falar".

Associando oralidade e os conhecimentos obtidos nas discussões que envolveram variação linguística, foi possível construir, em conjunto, um conceito de língua em que os alunos estavam inclusos. Grosso modo, língua foi compreendida como tudo que se fala dentro e fora da escola. Aparentemente é um conceito bem superficial, porém, valioso já que agrega aqueles que se sentem à margem da língua que os perpassa o tempo todo. Findei o estágio com uma mistura de sentimentos: feliz por ter conseguido proporcionar mudanças em alguns alunos, que passaram a ver a LP e as aulas de português sobre outro prisma; um tanto quanto triste por perceber que um sistema escolar engessado continua a ditar as regras que regem as aulas de português. 


\section{CONCLUSÃO}

As experiências obtidas no estágio supervisionado serão levadas para toda minha vida. Terei cada vez mais a certeza de que muito precisa ser feito para dissociar língua e gramática, uma vez que, algumas escolas ainda tomam a gramática tradicional como objeto de estudo nas aulas de português. Muitas das teorias estudadas na universidade parecem não se adequar com a realidade da escola. Quando estagiários chegamos nas escolas sedentos por mudanças, porém nos deparamos com um sistema de ensino extremamente rígido, tamanha é sua influência que causa estranheza nos alunos quando são submetidos às abordagens de ensino que rompem com padrão lousa-caderno.

No que tange às aulas de LP, reitero que é preciso que a escola repense o conceito de língua adotado; carece que escola e alunos falem a mesma língua. Uma escola que ensina LP sem abarcar a real língua falada pelos estudantes está a cumprir um papel exclusor, por isso a necessidade de uma nova roupagem para aulas de português em escolas públicas. A escola é um espaço de múltiplas culturas, logo, de múltiplas variantes de uma mesma língua; enquanto a escola continuar a erguer a bandeira da homogeneidade linguística, estará indo em mão oposta ao conceito de língua, como bem ressalta Bagno $(2007$, p. 38)

Pessoas de ambos os sexos, das mais diferentes faixas etárias, de múltiplas origens étnicas, de todas as classes sociais, de todos os graus de escolaridade, das mais diferentes profissões, das mais diferentes religiões, de diversas orientações sexuais, de diferentes opiniões políticas, vestidas de todos os modos possíveis etc. Como seria possível imaginar que toda essa gente, tão diversificada em tudo o mais, tivesse que falar sua língua sempre da mesma forma?

As discussões sobre concepção de língua e variação linguística precisam ganhar espaço no ambiente escolar, para que os alunos compreendam que eles não estão distantes/alheios da dinâmica da própria língua materna. Julgo que a abordagem de ensino proposta a essa turma foi um grande achado; mesmo não conseguindo resultados satisfatórios com todos os alunos, conseguimos aproximar uma parcela significativa da turma com as temáticas propostas para discussão em sala.

Quanto à gramática tradicional, esta se fez presente nas aulas, não de modo explícito e metódico; assuntos como: sujeito, verbo, adjetivo entre outros, foram trabalhados mediante a temática das culturas populares presentes no Brasil. Valendo-se de 
jogos e trabalhos com gêneros orais e escritos, nosso plano de ensino mostrou que é possível trabalhar a gramática de um jeito lúdico e leve, não apenas, abrir os horizontes dos estudantes acerca de um conceito abrangente de língua. Encerro esse relato de experiência com a frase do filósofo existencialista e escritor Jean-Paul Sartre, que resume toda a problematização trazida neste trabalho.

\author{
"Falamos na nossa própria língua e escrevemos numa língua \\ estrangeira".
}

\title{
REFERÊNCIAS
}

ANTUNES, I. C. Muito além da gramática: Por um ensino sem pedras no caminho. 1a edição. Belo Horizonte: Ed. Parábola, 2007.

AZEVEDO, R. Cultura da terra. 1 ed. São Paulo: Moderna, 2008.

BAGNO, M. Mas o que é mesmo variação linguística? In: BAGNO, M. Nada na língua é por acaso: por uma pedagogia da variação linguística. São Paulo: Parábola editorial, 2007, p.3457.

BAGNO, M. Preconceito linguístico: o que é, como se faz. São Paulo: Ed. Loyola, 1999.

BARBOSA, J. B. e DE CUBA, D. L. Crenças e atitudes linguísticas de alunos do Ensino Médio em escolas públicas de Uberaba. Todas as Letras-Revista de Língua e Literatura, v. 17, n. 1, p. 73-90, Uberaba, janeiro/abril de 2015.

BEZERRA, M. A. Ensino de língua portuguesa e contextos teórico-metodológicos. In: DIONÍSIO, A. P., MACHADO, A. R. e BEZERRA, M. A. (Org.) Gêneros textuais e ensino. Rio de Janeiro: Lucerna, 2002, p.37-46FIORIN, J. L. Linguagem e ideologia. 4 ed. São Paulo: Ática, 1995, p. 26-36.

BOAS, Franz. Antropologia cultural, - Rio de Janeiro: Jorge Zahar, 2004.

GÖRSKI, E. M. e COELHO, I. L. Variação linguística e ensino de gramática. Revista de Programa de Pós-Graduação em Linguística (PPGLg). Vol. 10 n.01, p. 73-91, Florianópolis, Janeiro de 2009.

MADEIRA, F. Crenças de professores de Português sobre o papel da gramática no ensino de Língua Portuguesa. Linguagem \& Ensino. Vol. 8 n.2, p. 17-38, Pelotas, 2005. 
RESENDE, M. L. M. Vygotsky: um olhar sociointeracionista do desenvolvimento da língua escrita. Disponível em: http://www.psicopedagogia.com.br/artigos/artigo.asp?entrlD=1195. Publicado em: 25 de novembro de 2009.

SUASSUNA, L. O ensino de Língua Portuguesa: problemas e perspectivas metodológicas. Tóp Educ. Vol. 13 n.1/2, p. 31-39, Recife, 1995.

WAAL, D. V. D. Gramática e ensino da língua portuguesa. In: IX Congresso Nacional de Educação - EDUCERE III Encontro Sul Brasileiro de Psicopedagogia, 2009, Curitiba, PR. Anais (online). Curitiba: Educere, 2009. Disponível em: http://www.educere.bruc.com.br. Acesso em 29 de junho de 2019.

Recebido em: 23 de Abril de 2020

Aceito para Publicação em 28 de maio de 2020 